\title{
PENGGUNANAAN COMPRESSION STOCKING TERHADAP PENCEGAHAN DEEP VENOUS THROMBOSIS (DVT): LITERATUR REVIEW
}

\author{
Najihah $^{1)}$ \\ ${ }^{1}$ Program Studi Ilmu Keperawatan, Universitas Muslim Indonesia (UMI) \\ email: najihah.najihah@umi.ac.id
}

\begin{abstract}
Deep Venous Thrombosis (DVT) is a condition in which a clot forms in deep vein due to inflammation/venous wall trauma or due to partial venous obstruction. Most DVT comes from lower extremities. Pulmonary embolism is a significant risk for DVT because the release of thrombus then follows the blood flow and is trapped in the pulmonary artery. Compression stocking is one of the compression therapies that helps prevent blood clots that form in the foot by applying pressure varies on each part of the foot. The purpose of this review literature is to determine the effectiveness of using the Compression stocking for prevention of DVT. The process of searching journal articles uses Google Scholar and several databases, namely Cocrane, Proques and Pubmed. Keywords included are "compression therapy", "compression stocking" and "deep venous thrombosis". Search results in each database based on keywords by reading the research abstract obtained 7 journal articles. The use of Compression stocking for prevention of DVT has been proven by several studies. This is because compression stocking works by exerting a compression level on the ankle with a gradual compression level. A pressure gradient or compression will ensure that blood flows towards the heart instead of reflux to the foot. But in the use of Compression stocking in the prevention of DVT, patients need to obtain information specifically about how to use it to avoid complications that might arise due to the use of Compression stocking.
\end{abstract}

Keywords: Deep Venous Thrombosis, Compression Stocking

\section{PENDAHULUAN}

Deep Venous Thrombosis (DVT) adalah kondisi dimana terbentuk bekuan dalam vena sekunder atau vena dalam dalam akibat inflamasi/trauma dinding vena atau karena obstruksi parsial vena. Kebanyakan DVT berasal dari ekstrimitas bawah. Penyakit ini dapat menyerang satu vena bahkan lebih. Vena-vena di betis adalah vena-vena yang paling sering terserang. Banyak yang sembuh spontan, dan sebagian lainnya berpotensi membentuk emboli. Vena-vena di betis adalah vena-vena yang paling sering terserang.Emboli paru-paru merupakan resiko yang cukup bermakna pada DVT karena terlepasnya trombus kemudian mengikuti aliran darah dan terperangkap dalam arteri pulmonalis (1).

DVT menyerang hampir 2 juta orang Amerika setiap tahunnya. Emboli paru adalah resiko yang cukup parah dari DVT dan terjadi pada 30\% pasien DVT. Emboli paru menyebabkan 60.000 kematian setiap tahunnya (1). Di Amerika diperkirakan bahwa 60.000-100.000 akan meninggal akibat dari DVT atau emboli paru dimana $10 \%-30 \%$ orang akan meninggal dalam waktu satu bulan setelah diagnosis. Kematian mendadak adalah gejala pertama dari $25 \%$ dari orang-orang dengan emboli paru. Diantara orang-orang-orang dengan DVT, $50 \%$ akan memiliki komplikasi jangka panjang (sindrom pasca-trombotik) dan sekitar 33\% dari orang-orang dengan DVT atau emboli paru akan memiliki kekambuhan dalam waktu 10 tahun (2).

Dalam sebuah survei epidemiologi, Komite Survei Penyakit Vena dari Japanesee Society of Phlebology pada tahun 1997 melaporkan bahwa DVT terjadi pada 506 pasien/tahun, sedangkan jumlah pasien baru dengan DVT diperkirakan 14.674 pasien/tahun, yaitu, 12/100.000 populasi/tahun dalam survei kuesioner yang dilakukan oleh Japanesee Society of Pulmonary Embolism Research tahun 2006. Temuan ini mencerminkan fakta bahwa kejadian DVT telah meningkat sekitar 30 kali lipat selama dekade terakhir (3). Angka mortalitas dan morbiditas akibat emboli paru menyebabkan pengobatan DVT ditekankan pada pencegahan emboli paru 
karena kedua proses tersebut saling berkaitan (1).

Dalam sebuah arikel yang berjudul "Guidelines for the Diagnosis, Treatment and Prevention of Pulmonary Thromboembolism and Deep Vein Thrombosis" dituliskan bahwa untuk memastikan pencegahan DVT berulang, pasien harus terus latihan dan terapi kompresi serta terapi antikoagulasi dalam jangka waktu yang tepat (3). Compression stocking merupakan salah satu dari terapi kompresi yang membantu mencegah penggumpalan darah yang terbentuk di kaki dengan menerapkan tekanan bervariasi pada setiap bagian kaki.

\section{METODE}

Langkah awal sebelum pencarian artikel jurnal yaitu menentukan topik dan menyusun pertanyaan penelitian. Elemen dalam pertanyaan penelitian, yaitu Population (P), intervention (I), comparison (C), outcome (O), dan time (T) (Susan et al, 2010). Adapun population $(\mathrm{P})$ yang diinginkan adalah pasien yang berisiko mengalami gangguan vaskular, intervention (I) yang diberikan yaitu Compression stocking, comparison (C) yaitu perawatan standar, dan outcome $(\mathrm{O})$ adalah hasil yang diinginkan yaitu pencegahan DVT dengan menggunakan Compression stocking dalam perawatan pasien yang berisiko megalami gangguan vascular.

Pada proses pencarian artikel jurnal, penulis menggunakan menggunakan Google Scholar dan beberapa database diantaranya yaitu Cocrane, Proques dan Pubmed. Kata kunci yang dimasukkan adalah kata kunci yang sesusi dengan PICOT yaitu "compression therapy", "compression stocking" dan "deep venous thrombosis" dibantu dengan penggunaan Boolean System (AND, OR, NOT) dan mathematic symbol (+, “"). Untuk lebih spesifik, maka dilakukan batasan pada tahun publikasi dengan waktu minimal 5 tahun terakhir yaitu 2010-2015. Hasil pencarian pada setiap database berdasarkan kata kunci dengan membaca abstrak penelitian dan yang dianggap paling sesuai dengan PICOT diperoleh 7 artikel jurnal.

\section{HASIL DAN PEMBAHASAN}

a. Compression Therapy dan Compression Stocking

Terapi kompresi yang melibatkan penerapan tekanan untuk ekstremitas bawah adalah komponen fundamental dalam pengelolaan gangguan vena kronis dan penyakit limfatik. Fungsi utamanya adalah untuk melawan gravitasi yang merupakan faktor kunci untuk gangguan aliran balik vena dan limfatik dari ekstremitas bawah (4). Terapi kompresi merupakan perawatan yang paling banyak digunakan untuk pada pasien Venous Leg Ulcer (VLU), dan telah dimanfaatkan dalam berbagai bentuk selama lebih dari 4 abad. Aplikasi tekanan eksternal untuk otot betis menimbulkan tekanan interstitial sehingga meningkatkan aliran balik vena dan pengurangan hipertensi vena. Keberhasilan penyembuhan VLU dengan terapi kompresi secara luas bervariasi dari $40 \%$ sampai 95\% dan sejumlah penelitian telah menunjukkan bahwa sistem kompresi dengan nilai tekanan sub-perban berkisar dari 35 mmHg-45 mmHg memberikan hasil yang terbaik untuk mencapai tingkat penyembuhan (5). Kompresi elastis hingga $40 \mathrm{mmHg}$ tidak menghambat perfusi arteri tetapi dapat menyebabkan normalisasi fungsi pemompaan vena yang berkurang. Kompresi mampu meningkatkan hemodinamik vena dan mengurangi edema (6). Efek hemodinamik telah dibuktikan dengan mengukur volume dan kecepatan aliran vena menggunakan MRI, Duplex dan radioisotop, mengukur refluks dan fungsi pompa vena menggunakan plethysmography dan phlebodynamometry dan pengurangan Edema dapat diukur dengan limb volumetry (4). Compression therapy sering digunakan sebagai terapi dalam kondisi insufisiensi vena dan limfatik dalam tungkai bawah, termasuk varises, lymphedema, eksim vena dan ulserasi, trombosis vena dalam dan sindrom pascatrombosis. Banyak bentuk Compression therapy termasuk elastis dan nonelastic perban, sepatu, kaus kaki atau stocking dan pneumatik devices (7).

Compression stocking bekerja dengan mengerahkan tingkat kompresi di pergelangan kaki dengan tingkat kompresi yang diturunkan secara bertahap. Gradien tekanan atau kompresi akan memastikan bahwa darah mengalir menuju jantung bukan refluks ke kaki karena dapat mengurangi diameter pembuluh darah besar yang meningkatkan kecepatan dan volume aliran darah. Compression stocking diklasifikasikan menurut tekanan kompresi yang diarahkan ke kaki. Secara umum, dibagi menjadi tiga yaitu (a) kompresi tekanan rendah 
dengan tekanan $<20 \mathrm{mmHg}$, (b) kompresi tekanan sedang dengan tekanan $20-30 \mathrm{mmHg}$, dan (c) kompresi tekanan tinggi dengan tekanan $>30 \mathrm{mmHg}$. Tekanan keseluruhan dipengaruhi oleh faktor-faktor seperti elastisitas dan kekakuan bahan stocking, ukuran dan bentuk kaki si pemakai, dan gerakan dan aktivitas pemakainya (7).

\section{b. Compression Stocking untuk mencegah DVT}

Pada peneltian berjudul "Knee length versus thigh length graduated compression stockings for prevention of deep vein thrombosis in postoperative surgical patients" yang dilakukan oleh Sajid, et. al (2012) dengan menganalisis secara Randomized-Controled Trial (RCT) untuk mengvaluasi efektivitas Knee length (KL) dan thigh length (TL) compression stockings sebagai thromboprophylaxis pada pasien rawat inap yang menjalani berbagai jenis operasi. Hasil penelitian ini menunjukkan tidak ada perbedaan yang signifikan dalam efektivitas dari kedua jenis compression stocking tersebut untuk mengurangi kejadian DVT pada pasien pasca-operasi (OR) 1,55; 95\% CI 0,78-3,07; $\mathrm{P}=0,21)(8)$. Tekanan yang diberikan oleh compression stocking terbesar di pergelangan kaki dan kemudian secara bertahap menurun di betis. Sehingga secara teori LT compression stocking mendistribusikan efek mekanik dengan proporsi yang lebih besar pada kaki disbanding KT compression stocking.

Penelitian ini didukung oleh sebuah Evidance yang menunjukkan bahwa compression stocking yang memberikan tekanan $\sim 20 \mathrm{mmHg}$ pada bagian distal kaki dapat meningkatkan kecepatan aliran darah vena dalam posisi terlentang dan mencegah kaki bengkak setelah lama duduk atau berdiri. Dalam posisi tegak, tekanan $>50 \mathrm{mmHg}$ dibutuhkan untuk pengurangan hipertensi vena selaa berjalan. Tekanan puncak menimbulkan "efek memijat" yang lebih baik oleh compression stocking dibanding elastic perban (4). Sehingga compression therapy menjadi landasan dalam pengelolaan pasien dengan insufisiensi vena dan limfatik.

Penelitian ini sejalan dengan penelitian yang dilakukan oleh Sachdeva, et. al (2014) yang bertujuan untuk mengevaluasi efektivitas dan keamanan compression stocking dalam mencegah DVT dalam berbagai kelompok pasien yang dirawat di rumah sakit. Hasil penelitian menunjukkan bahwa pasien yang memakai compression stocking yang mengalami DVT lebih rendah yaitu 9\% dari 1.391 sampel, dibandingkan pasien tanpa compression stocking yaitu $21 \%$ dari 1.354 sampel (OR 0,33; 95\% CI 0,26-0,41; P $<0,00001)$. Jadi compression stocking efektif dalam mengurangi risiko DVT pada pasien rawat inap, khususnya pada penggunaannya di bedah umum dan ortopedi (9). Namun, penelitian terbatas untuk pasien medis (nonbedah) karena hanya satu studi yang menunjukkan efektivitas compression stocking dalam mencegah DVT pada pasien non-bedah.

\section{c. Compression stocking untuk mencegah Post-trombotic Syndrome pada pasien DVT}

Post-trombotic Syndrome (PTS) adalah komplikasi kronis yang paling penting dari DVT. PTS berkembang di sepertiga sampai setengah dari pasien DVT. Berdasarkan insiden dan prevalensi yang tinggi, PTS adalah komplikasi yang paling sering dari DVT (10).

Penelitian "Venous Compression for Prevention of Post-thrombotic Syndrome: A Meta-analysis" yang bertujuan untuk menetukan efektivitas compression stocking pada pengurangan PTS pada pasien DVT, dari 5 percobaan acak pada pasien dengan DVT akan dibandingkan pengobatan dengan kompresi vena terhadap kontrol. Hasil penelitian menujukkan bahwa PTS ringan-sedang terjadi pada 64 dari 296 (22\%) pasein dengan kompresi vena, dibandingkan dengan 106 dari $284(37 \%)$ pasien kontrol (RR 0,52); PTS parah terjadi di 14 dari 296 (5\%) pasein dengan kompresi vena, dibandingkan dengan 33 dari 284 (12\%) pasien kontrol (RR 0,38). Sehingga dapat disimpulkan, kompresi vena dengan compression stocking mengurangi kejadian PTS, terutama PTS parah (11). Namun, penyelidikan lebih lanjut diperlukan untuk variasi luas dan jenis stoking yang digunakan, interval waktu dari diagnosis ke pemakaian stocking, dan durasi pengobatan. Penelitian ini sejalan dengan penelitian yang dilakukan Subbiah, et. al (2014) yang bertujuan untuk mengetahui efektivitas compression stocking untuk mencegah PTS pada pasien dengan DVT. Hasil penelitian ini menunjukkan bahwa jika dibandingkan dengan kelompok kontrol, pasien DVT yang menggunakan compression stocking memiliki risiko lebih rendah untuk kejadian PTS (RRR 0,72; 95\% CI 0,56-0,91; $\mathrm{p}=0,005)$. Sehingga dapat 
disimpulkan, pada pasien DVT, penggunaan compression stocking dikaitkan dengan risiko lebih rendah menderita PTS (12).

Penelitian ini bertolakbelakang dengan penelitian Khan, et. al (2013) yang bertujuan untuk menilai efektivitas dari Elastis Compression Stocking (ECS) untuk pencegahan PTS. Yang membedakan dengan peneltian sebelumnya, pada peneltian ini digunakan control placebo. Dari 410 pasien yang secara acak menerima ECS aktif dan 396 plasebo, jumlah Insiden PTS adalah 14,2\% pada kelompok ECS dan $12,7 \%$ pada kelompok placebo (95\% CI 0,73-1,76; $\mathrm{p}=$ 0,58). Jadi dapat disimpulkan bahwa ECS tidak mencegah PTS setelah DVT, sehingga penelitian tidak mendukung pemakaian rutin ECS setelah DVT untuk mencegah PTS (13).

\section{d. Penggunaan Compression Stocking}

Compression Stocking umumnya aman untuk digunakan, dengan sedikit komplikasi. Penggunaan stocking yang salah menyebabkan ketidaknyamanan dan dapat menyebabkan nekrosis akibat tekanan. Penggunaan compression stocking pada kaki dengan aliran arteri yang terganggu dapat memperburuk ischemia. Pasien yang alergi terhadap bahan stocking dapat menimbulkan dermatitis kontak, perubahan warna kulit dan rasa panas. Komplikasi compression stocking dapat dicegah jika pasien dinilai, diukur dan dipasang dengan tepat. Tingkat ketidakpatuhan penggunaan compression stocking dilaporkan 30\%-65\% dengan alasan termasuk rasa sakit, ketidaknyamanan, kesulitan mengenakan stocking, panas yang berlebihan, dan iritasi kulit (7).

Salah satu penelitian yang terkait dengan penggunaan compression stocking yaitu "Investigate of Eligibility Usage of Graduated Compression Stockings" yang dilakukan oleh Dirimese, et. al (2012). Penelitian ini bertujuan menguji kesesuaian penggunaan compression stocking. Hasil penelitian menunjukkan dari $77,5 \%$ pasien yang menggunakan compression stocking yang diperoleh dari tenaga kesehatan, 58,8\% mengetahui bagaimana menggunakan compression stocking dan $29,8 \%$ mengalami kesulitan dalam penggunaan compression stocking. Selain itu dari $96,5 \%$ pasien memperoleh ukuran stocking yang tepat, 92,1\% menggunakan dengan benar, 30,7\% melepas stoking setiap hari dan memeriksa kulit, 21,9\% mengalami kerutan dan longgar, 19,3\% p mengalami curling up dari stocking yang menciptakan efek tourniquet. 32,5\% mengalami peningkatan panas di kedua kakinya, 30,7\% pasien gatal, 11,4\% mengalami kepekaan, dan $8,8 \%$ berpengalaman ertyhema dan mati rasa. Dapat disimpulkan bahwa mayoritas pasien memperoleh informasi tentang penggunaan compression stocking untuk mencegah DVT dari tenaga kesehatan Namun, mereka memiliki pengetahuan yang terbatas tentang bagaimana cara menggunakannya (14) Hal ini membuktikan bahwa pasien memiliki kesulitan dalam penggunaan compression stocking. Dalam pencegahan DVT, pendidikan pasien penting untuk menjamin keselamatan pasien.

\section{KESIMPULAN}

Dari pembahasan di atas maka dapat ditarik beberapa kesimpulan yaitu ;

a. Compression stocking adalah salah satu metode terapi kompresi yang melibatkan penerapan tekanan pada ekstremitas bawah. Fungsi utamanya adalah untuk melawan gravitasi yang merupakan faktor kunci terjadinya gangguan aliran balik vena dan limfatik pada ekstremitas bawah.

b. Penggunanaan Compression stocking untuk pencegahan DVT dan pencegahan resiko post-trombotic syndrom telah dibuktikan oleh beberapa penelitian. Hal ini karena compression stocking bekerja dengan mengerahkan tingkat kompresi di pergelangan kaki dengan tingkat kompresi yang diturunkan secara bertahap. Gradien tekanan atau kompresi akan memastikan bahwa darah mengalir menuju jantung bukan refluks ke kaki.

c. Dalam penggunaan Compression stocking dalam pencegahan DVT, pasien perlu memperoleh informasi khususnya tentang cara pengunaannya untuk menghindari komplikasi yang mungkin timbul akibat pemakain Compression stocking.

\section{REFERENSI}

1. Price SA, Wilson LM. Patofisiologi : Konsep Klinis Proses-proses Penyakit Edisi 6 Volume! Jakarta: EGC; 2006.

2. CDC. www.cdc.gov. [Online]. United South America: Departement of Health \& Human Service; 2015 [cited 2016 Mei 29. Available from: 
http://www.cdc.gov/ncbddd/dvt/data.html.

3. JCS Joint Working Group. Guidelines for the Diagnosis, Treatment and Prevention of Pulmonary Thromboembolism and Deep Vein Thrombosis (JCS 2009). Circulation Journal. 2011;: p. 1258-1281.

4. Partsch H. Compression Therapy: Clinical and Experimental Evidence. Annals of Vascular Diseases. 2012 August; 5: p. 416422.

5. Milic DJ, Zivic SS, Bogdanovic DC, Jovanovic MM, Jankovic RJ, Milosevic ZD, et al. The influence of different sub-bandage pressure values on venous leg ulcers healing when treated with compression therapy. The American Venous Forum. 2010;: p. 655-661.

6. Mosti G, Iabichella ML, Partsch H. Compression therapy in mixed ulcers increases venous output and arterial perfusion. The American Venous Forum. 2012;: p. 122-128.

7. Lim CS, Davies AH. Graduated Compression Stockings. Canadian Medical Association Journal. 2014 July 8; 10: p. 391-398.

8. Sajid MS, Desai M, Morris RW, Hamilton G. Knee length versus thigh length graduated compression stockings for prevention of deep vein thrombosis in postoperative surgical patients. Cochrane Vascular Group. 2012;: p. $1-13$.

9. Sachdeva A, Dalton M, Amaragiri SV, Lees T. Graduated Compression Stockings for Prevention of Deep Vein Thrombosis. Cochrane Database of Systematic Reviews. 2014;(12).

10. Kahn SR. The Post-Thrombotic Syndrome. American Society of Hematology. 2010;: p. 215-220.

11. Musani MH, Matta F, Yaekoub AY, Liang J, Hull RD, Stein PD. Venous Compression for Prevention of Postthrombotic Syndrome: A Meta-analysis. The American Journal of Medicine. 2010;: p. 735-740.

12. Subbiah R, Aggarwal V, Bashir R. Co mpress ion Stockings Us e to Prevent Pos t Thrombo tic Syndrome in DVT Patients: A MetaAnalysis of Randomized Co ntrol Studies. Journal American College of Cardiology. 2014;: p. 20-34.

13. Kahn SR, Shapiro S, Wells PS, Rodger MA, Kovacs MJ, Anderson DR, et al. Compression stockings to prevent post- thrombotic syndrome: a randomised placebocontrolled trial. The Lancet. 2013;: p. 1-11.

14. Dirimese E, Yavuz M, Nurulke B. Investigate of Eligibility Usage of Graduated Compression Stockings. International Journal of Caring Sciences. 2012;: p. 354-361. 